\title{
The effect of subchronic supplementation with folic acid on homocysteine induced seizures
}

\author{
A Rasic-Markovic ${ }^{1}$, B Rankov-Petrovic ${ }^{1}$, D Hrncic ${ }^{1}$, D Krstic ${ }^{2}$, M Colovic ${ }^{3}$, \\ Dj Macut ${ }^{4}$, D Djuric ${ }^{1}$, O Stanojlovic ${ }^{1}$ \\ ${ }^{1}$ Institute of Medical Physiology "Richard Burian", Faculty of Medicine, University of Belgrade, Belgrade, Serbia \\ ${ }^{2}$ Institute of Chemistry, School of Medicine, University of Belgrade, Belgrade, Serbia \\ ${ }^{3}$ Institute of Nuclear Sciences, "Vinča", Belgrade, Serbia \\ ${ }^{4}$ Institute of Endocrinology, Diabetes and Metabolic Diseases, Clinical Center Belgrade, Belgrade, Serbia
}

Received: December 11, 2014

Accepted after revision: March 7, 2015

Influence of folic acid on the CNS is still unclear. Folate has a neuroprotective effect, while on the other hand excess folate can exacerbate seizures in epileptics. The aim of the present study was to examine the effect of subchronic administration of folic acid on behavioural and electroencephalographic (EEG) characteristics of DL homocysteine thiolactone induced seizures in adult rats. The activity of $\mathrm{Na}^{+} / \mathrm{K}^{+}$-ATPase and $\mathrm{Mg}^{2+}$-ATPase in different brain regions was investigated. Adult male Wistar rats were divided into groups: 1 . Controls $(\mathbf{C}, 0.9 \% \mathrm{NaCl}) ; 2$. DL homocysteine-thiolactone $8.0 \mathrm{mmol} / \mathrm{kg}(\mathbf{H}) ; 3$. Subchronic supplementation with folic acid $5 \mathrm{mg} / \mathrm{kg}$ for 7 days $(\mathbf{F})$ and 4. Subchronic supplementation with F + single dose of H (FH). Seizure behaviour was assessed by incidence, latency, number and intensity of seizure episodes. Seizure severity was described by a descriptive scale with grades 0-4. For EEG recordings, three gold-plated recording electrodes were implanted into the skull. Subchronic supplementation with folic acid did not affect seizure incidence, median number of seizure episodes and severity in FH, comparison with $\mathrm{H}(p>0.05)$. The majority of seizure episodes in all groups were of grade 2 . There were no significant differences in lethal outcomes at $24 \mathrm{~h}$ upon $\mathrm{H}$ injection in the $\mathrm{FH}$ vs. $\mathrm{H}$ group. The activity of $\mathrm{Na}^{+} / \mathrm{K}^{+}-$ ATPase and $\mathrm{Mg}^{2+}$-ATPase was significantly increased in almost all examined structures in the FH vs. $\mathrm{H}$ group. Subchronic folic acid administration did not exacerbate $\mathrm{H}$ induced seizures and completely recovered the activity of ATPases.

Keywords: subchronic folic acid, DL homocysteine thiolactone, seizures, electroencephalography, rats

Folic acid, also referred to as folate, is one of the 13 essential vitamins obtained from dietary sources or supplements. Among water soluble group B vitamins, folates have attracted much scientific and public health interest in recent years (7). Folate consists of the pteridine ring to which p-aminobenzoic acid is attached and one or more glutamate residues, the latter being the major excitatory neurotransmitter in the brain (28).

Folates are required both in the remethylation of homocysteine to methionine and in the synthesis of S-adenosyl-methionine (SAM), the principal biological methyl donor in numerous methylation reactions $(14,45)$. Methylation of DNA, RNA and proteins by SAM is an important epigenetic determinant in gene expression, DNA stability, DNA integrity and mutagenesis. Folate also plays an essential role in the de novo synthesis of purines and

Corresponding author: Prof. Dr. Olivera Stanojlović, $\mathrm{MD}, \mathrm{PhD}$

School of Medicine, University of Belgrade

Višegradska 26/II, 11000 Belgrade, Serbia

Phone/Fax: +381-11-3607-106; E-mail: solja@afrodita.rcub.bg.ac.rs 
thymidylate, which is required in DNA replication and repair (20). Folate, via its donation of a methyl group, plays a key role in neurotransmitter synthesis and myelin synthesis and repair (12).

Decades of research suggest that maternal folate deprivation might be a cause of neural tube defect $(35,49)$ and childhood brain tumors $(10)$. Folate deficiency has been associated with reduced hippocampal and amygdalar volumes and global brain atrophy in humans $(8,41)$.

An adequate amount of folate is required to maintain low levels of homocysteine in the central nervous system (CNS), which may exert direct neurotoxic and pro-oxidative actions $(15,22)$. A growing number of epidemiological studies have linked folate deficiency and resultant elevated plasma total homocysteine levels with an increased risk of vascular disease, cerebral ischemia, seizures and neurodegenerative and neuropsychiatric diseases, including Alzheimer's and Parkinson's disease $(29,31)$. Some reports have shown that folic acid administration can reduce blood homocysteine concentrations in humans and rats $(23,38)$ and reduce the risk for these diseases (44).

Homocysteine is a sulphur-containing amino acid recently recognized as one of the most potent excitatory agents of the central nervous system $(9,34)$ and the major risk factor for numerous brain disorders like cognitive decline and dementia, Alzheimer's, Parkinson's and Huntington's disease $(19,39)$ and epilepsy (13). Stanojlović et al. (42) have recently showed that acute administration of homocysteine to adult rats significantly alters neuronal circuits, leading to epileptogenic activity and convulsive episodes in adult rats.

$\mathrm{Na}^{+} / \mathrm{K}^{+}$-ATPase is a key enzyme involved in the maintenance of brain excitability and some authors reported elevated $\mathrm{Na}^{+} / \mathrm{K}^{+}$-ATPase activity in certain animal models of epilepsy (3). On the other hand, reduced activity of this enzyme was found in cerebral ischemia (47), epilepsy (11) and neurodegeneration (24) and it possibly correlates with excitotoxic mechanisms.

In view of these considerations, the aim of the present study was to examine the effect of subchronic supplementation with folic acid on DL homocysteine thiolactone induced seizures and on brain $\mathrm{Na}^{+} / \mathrm{K}^{+}$-ATPase and $\mathrm{Mg}^{2+}$-ATPase activity.

\section{Materials and Methods}

\section{Animals and experimental conditions}

All experimental procedures were carried out in accordance with The European Council Directive (86/609/EEC), and were approved by the Animal Care Committee of the University of Belgrade (298/5-2).

Adult male Wistar rats (170-200 g), obtained from the Military Medical Academy Breeding Laboratories, Belgrade (Serbia) were used. The animals were housed individually in transparent plastic wire-covered cages $(55 \times 35 \times 15 \mathrm{~cm})$ with free access to food and water, under controlled ambient conditions $\left(22-23{ }^{\circ} \mathrm{C}, 50-60 \%\right.$ relative humidity, $12 / 12 \mathrm{~h} \mathrm{light/dark}$ cycle with light switched on at 8 a.m.). All tests took place during light period, between 8:00 and 16:00 $\mathrm{h}$. The acclimatization period lasted for 7 days.

\section{Study design and experimental procedures}

The animals were divided into the following groups: 1 . Controls, saline-injected $(\mathbf{C}, 0.9 \%$ $\mathrm{NaCl}, n=10) ; 2$. DL homocysteine-thiolactone $8.0 \mathrm{mmol} / \mathrm{kg}(\mathbf{H}, n=9) ; 3$. Subchronic supplementation with folic acid $5 \mathrm{mg} / \mathrm{kg}$ for 7 days $(\mathbf{F}, n=8)$ and 4 . Subchronic supplementation with folic acid for 7 days (FA) + single dose of HT (FH, $n=9)$. 
Each rat was used only once. All the substances were freshly dissolved in saline and after adjusting the $\mathrm{pH}$ to 7.4 , administered intraperitoneally (i.p.) in a volume of $0.1 \mathrm{ml} / 100$ g rat body weight.

\section{Behavioural recordings}

Behavioural manifestations of homocysteine induced epilepsy in rats were recorded. The animals placed in separate transparent plastic cages $(55 \times 35 \times 15 \mathrm{~cm})$ were observed for 120 min for the occurrence of convulsive behaviour. This was assessed by the incidence of seizures (the number of convulsing animals out of the total number of rats), the number of seizure episodes per rat and the seizure severity. Seizure severity was determined by a modified descriptive rating scale reported by Stanojlović et al. (42) with grades defined as: grade 1 - head nodding, lower jaw twitching; grade 2 - myoclonic body jerks (hot plate reaction), bilateral forelimb clonus with full rearing (Kangaroo position); grade 3 progression to generalized clonic convulsions followed by tonic extension of fore and hind limbs and tail and grade 4 - prolonged severe tonic-clonic convulsions lasting over $10 \mathrm{sec}$ (status epilepticus) or frequent repeated episodes of clonic convulsions for an extended period of time (over $5 \mathrm{~min}$ ). In addition, latency to seizure, defined as a time from $\mathrm{H}$ injection to the first seizure episode, was also recorded. For rats without seizures, 90 min latency time was scored. Lethality was recorded $90 \mathrm{~min}$ and $24 \mathrm{~h}$ after homocysteine administration.

\section{Surgery and EEG recordings}

The rats were anesthetized with pentobarbital sodium $(50 \mathrm{mg} / \mathrm{kg}$, i.p. $)$, placed in a stereotaxic apparatus and three gold-plated recording electrodes were implanted over frontal, parietal and occipital cortices (for details see ref 42). Animals were allowed at least 7 days recovery from the surgery and then acclimated to the recording environment for at least $24 \mathrm{~h}$. During that period, animals were supervised for the occurrence of convulsive behaviour.

An 8-channel EEG apparatus (RIZ, Zagreb, Croatia) was used. The signals were digitized using a SCB-68 data acquisition card (National Instruments Co, Austin, Texas, USA). A sampling frequency of $512 \mathrm{~Hz} /$ channel and 16-bit A/D conversion were used for the EEG signals. The cut-off frequencies for EEG recordings were set at $0.3 \mathrm{~Hz}$ and $80 \mathrm{~Hz}$ for the high-pass and low-pass filters, respectively. Ambient noise was eliminated using a $50 \mathrm{~Hz}$ notch filter. Data acquisition and signal processing were performed with LabVIEW software developed in the laboratory (NeuroSciLaBG).

All EEG recordings in freely moving rats were visually monitored and screened for seizure activity and stored on disk for subsequent off-line analysis. The power spectral density (PSD) of the characteristic $12 \mathrm{~s}$ epochs was calculated. The fast Fourier transform method (linear detrending, Hanning window, $0.083 \mathrm{~Hz}$ resolution) was applied to obtain estimates of total PSD $\left(\mu \mathrm{V}^{2} / \mathrm{Hz}\right)$. Epochs with artifacts and with a significant amount of contamination by electromyographic activity were carefully detected and excluded from the analysis. The rats were removed from the recording chambers and returned to its home cages upon completion of the $120 \mathrm{~min}$ recording sessions.

\section{Biochemical analyses}

In a separate series of experiments, the activity of $\mathrm{Na}^{+} / \mathrm{K}^{+}$-ATPase and $\mathrm{Mg}^{2+}$-ATPase in the cortex, the hippocampus and the brain stem in the following groups $\mathrm{C}, \mathrm{H}, \mathrm{F}$ and $\mathrm{FH}(n=16$ per group) were analyzed. 


\section{Synaptic plasma membrane preparation}

Animals were killed without anesthesia by decapitation and the brains rapidly excised. The cortex, hippocampus and brain stem were dissected out and pooled (6/pool) for immediate preparation of synaptic plasma membranes (SPM). The SPM from the cortex, the hippocampus and the brain stem were isolated as described by Cohen et al. (6) and modified by Towle and Sze (46). Mitochondrial contamination and protein content were determined according to the standard procedure (16).

\section{ATPase assays}

SPM ATPase activities were assayed in a standard medium consisting of $50 \mathrm{mM}$ Tris- $\mathrm{HCl}$, $\mathrm{pH} 7.4,100 \mathrm{mM} \mathrm{NaCl}, 20 \mathrm{mM} \mathrm{KCl}$ and $5.0 \mathrm{mM} \mathrm{MgCl}$ and $25 \mu \mathrm{g}$ of SPM proteins were added. Incubation mixtures were preincubated for $10 \mathrm{~min}$ at $37^{\circ} \mathrm{C}$. The reaction was initiated by the addition of $2.0 \mathrm{mM}$ ATP to a final volume of $200 \mu$. The reaction was terminated after 10 min by adding $22 \mu \mathrm{lice-cold} 3.0 \mathrm{M} \mathrm{HClO}_{4}$ and immediately cooled with ice. The inorganic orthophosphate $(\mathrm{Pi})$ released by ATP hydrolysis was measured using a modified spectrophotometric procedure (48) by reading the absorbance at $690 \mathrm{~nm}$. The activity obtained in the absence of $\mathrm{NaCl}$ and $\mathrm{KCl}$ was attributed to $\mathrm{Mg}^{2+}$-ATPase. $\mathrm{Na}^{+} / \mathrm{K}^{+}$-ATPase activity was calculated as the difference between the total ATPase (obtained in the presence of $\mathrm{Na}^{+}, \mathrm{K}^{+}$and $\mathrm{Mg}^{2+}$ ions) and $\mathrm{Mg}^{2+}$-ATPase activity.

SPM ATPase activities were determined in pooled brain tissues (cortex, hippocampus and brain stem). The results are expressed as mean of specific enzyme activity \pm SD from at least four independent experiments done in triplicates. Specific enzymatic activities are expressed as $\mu \mathrm{M}$ of inorganic phosphate released per mg protein per hour.

\section{Drugs}

All drugs were of analytical purity and purchased from Sigma-Aldrich Chemical Co., USA.

\section{Data analyses, statistical analyses}

Significance of the differences in the incidence of seizures and lethality was evaluated by Fisher's exact probability test. Since the normal distribution of the data on seizure latency, number and intensity of seizure episodes have not been estimated by Kolmogorov-Smirnov test, the non-parametric analyses (Kruskal-Wallis ANOVA and Mann-Whitney $U$-test) were used to determine the statistical significance of the differences between the groups $\left({ }^{*} p<0.05\right.$, $\left.{ }^{* *} p<0.01\right)$. The results were expressed as medians with $25^{\text {th }}$ and $75^{\text {th }}$ percentiles.

The significance of the differences in the activity of $\mathrm{Na}^{+} / \mathrm{K}^{+}$-ATPase and $\mathrm{Mg}^{2+}$-ATPase between the groups was estimated by Student's $t$-test. The results are expressed as the means \pm SD.

\section{Results}

\section{Seizure behaviour}

Animals in the $\mathrm{C}$ and $\mathrm{F}$ groups, expressed normal gross behavioural activity without any signs of seizures and no lethality was recorded. Convulsions were observed in all rats that received DL homocysteine-thiolactone at a dose of $8 \mathrm{mmol} / \mathrm{kg}$. Subchronic supplementation with folic acid did not affect seizure incidence in the $\mathrm{FH}(77.7 \%, p>0.05)$ in comparison with the $\mathrm{H}(100.00 \%)$ group (Fig. 1). 


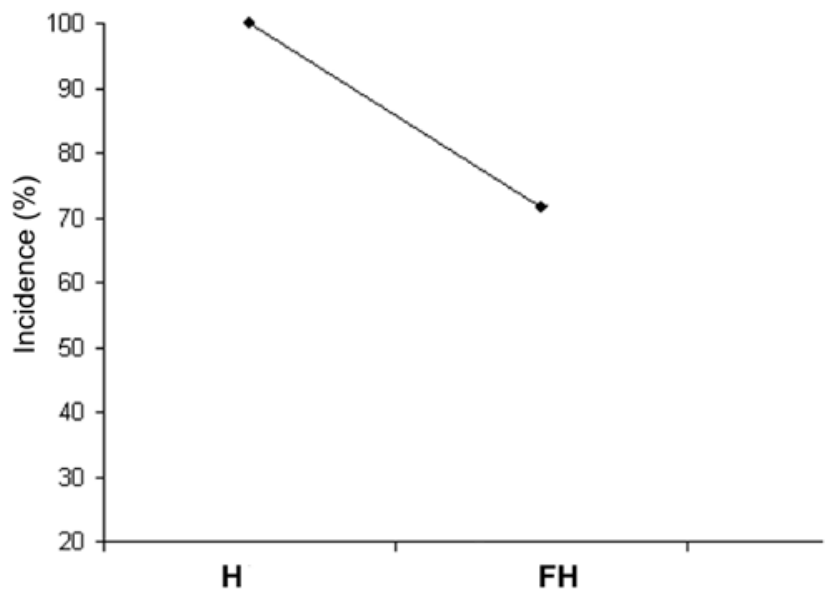

Fig. 1. The effect of subchronic supplementation with folic acid on seizure incidence in experimental groups.

Wistar rats were i.p. treated with DL homocysteine-thiolactone $8 \mathrm{mmol} / \mathrm{kg}(\mathrm{H})$ or with folic acid

( $5 \mathrm{mg} / \mathrm{kg}$ for 7 days) prior to $\mathrm{H}$ injection $(\mathrm{FH})$. The significance of the differences between the groups was estimated by Fisher's exact probability test

Folic acid supplementation decreased the median latency to the first seizure episode in the FH [20.0 (17.7-90.0) $\mathrm{min}](p>0.05)$ compared to the H group [28.0 (21.0-39.0) min] but not significantly (Fig. 2A). Median number of seizure episodes per rat in FH [2.00 (0.00 $6.00)](p>0.05)$ were not affected by subchronic supplementation with folic acid, compared to the $\mathrm{H}[4.00$ (1.00-5.00)] group (Fig. 2B). Median seizure episode severity was not affected by folic acid supplementation [2.00 (1.00-4.00)] compared to the group H [2.00 (1.00-4.00)] (Fig. 2C).

In order to examine the seizure severity, the statistical significance of seizure episode severity distribution was estimated by Fisher's exact probability test. The majority of seizure episodes in all groups: H (36.0\%) and FH (50.0\%) were of grade 2 (Table I). Folic acid supplementation increased lethal outcomes 90 min after $\mathrm{H}$ injection in the $\mathrm{FH}$ group $(77.7 \%)$ but statistical significance was not attained when compared to the $\mathrm{H}(44.4 \%)$. There were no significant differences in lethal outcomes $24 \mathrm{~h}$ upon $\mathrm{H}$ injection in $\mathrm{FH}$ comparing to the $\mathrm{H}$ group (Table II).

\section{EEG analysis}

Bioelectrical activity recorded from the frontal, parietal and occipital cortex in the group of rats treated only with folic acid was similar to the one in the control group, revealing no epileptiform graph elements, while PSD was dominant in the alpha frequency range.

The first signs of bioelectrical activity of the group treated with $\mathrm{H}$ were isolated spikes, which progressed to the spike wave complexes and burst of spikes. After $45 \mathrm{~min}$ of DL homocysteine-thiolactone administration and during grade 2 in the $\mathrm{FH}$ group, we recorded generalized high-voltage synchronous bursts of polyspikes in EEG that have been higher amplitude and PSD compared to the H group (Fig. 3). Dissociation between EEG pattern and motor phenomena, as well as low electroclinical correlation was common to all experimental recordings. 
A

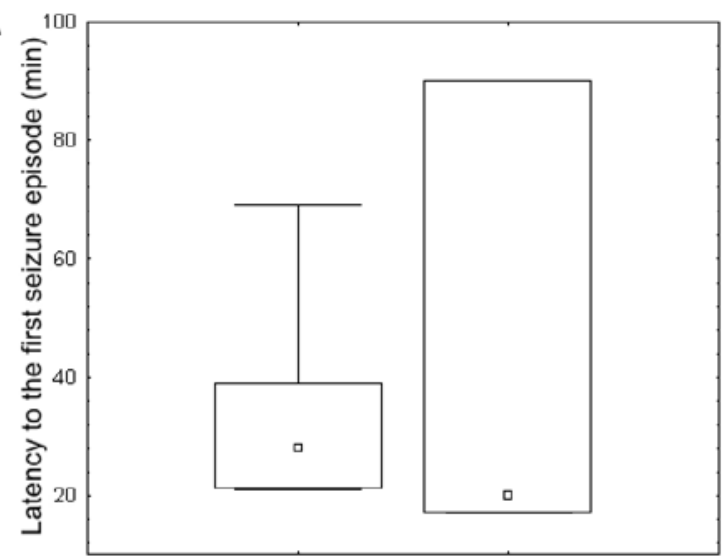

B

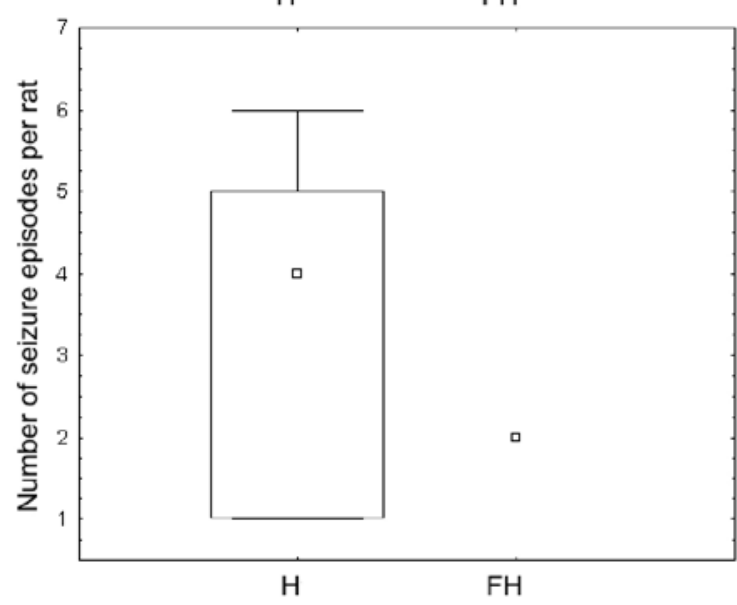

C

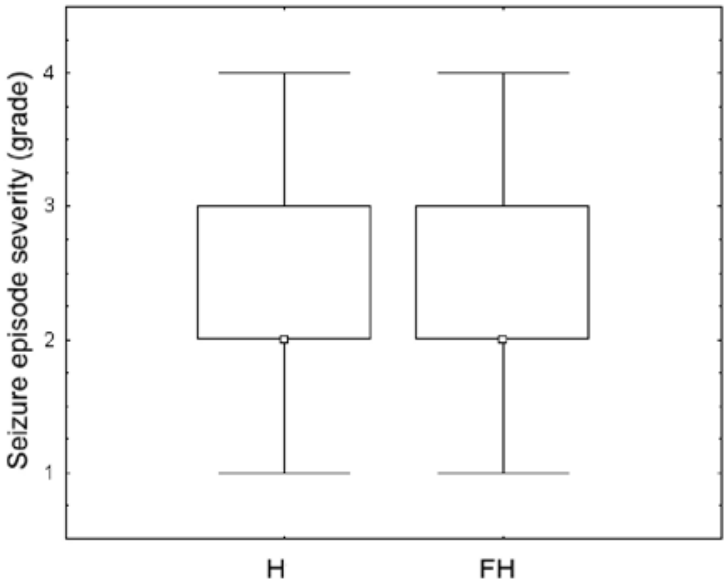

I Min-Max

$25 \%-75 \%$

- Median
I Min-Max

$\square 25 \%-75 \%$

a Median
I Min-Max

$25 \%-75 \%$

- Median

Fig. 2. The effect of subchronic supplementation with folic acid on median latency to the first seizure episode (A), a number of seizure episodes per rat $(\mathbf{B})$ and seizure severity $(\mathbf{C})$.

The significance of the differences between the groups was estimated by Kruskal-Wallis ANOVA and MannWhitney $U$-test. For the details see caption to Fig. 1 
Table I. The effect of subchronic folic acid supplementation on seizure severity grade distribution in experimental groups

\begin{tabular}{|c|c|c|c|}
\hline \multirow{2}{*}{ Grade (\%) } & H & FH & Significance \\
\cline { 2 - 4 } & 16.0 & 6.25 & $p>0.05$ \\
\hline 1 & 36.0 & 50.0 & $p>0.05$ \\
\hline 2 & 28.0 & 37.5 & $p>0.05$ \\
\hline 3 & 20.0 & 6.25 & $p>0.05$ \\
\hline 4 & &
\end{tabular}

Severity of seizure episode was assessed by descriptive rating scale with defined grades $1-4$. Statistical significance of the differences was estimated by Fisher's exact probability test.

For the details see caption to Fig. 1

Table II. The effect of subchronic folic acid supplementation on lethality recorded $90 \mathrm{~min}$ and $24 \mathrm{~h}$ after DL-homocysteine thiolactone administration

\begin{tabular}{|l|c|c|c|}
\hline \multirow{2}{*}{ Lethality (\%) } & \multicolumn{2}{|c|}{ Experimental groups } & Significance \\
\cline { 2 - 4 } & H & FH & \\
\hline After 90 min & 44.4 & 77.7 & $p>0.05$ \\
\hline After 24 h & 88.8 & 77.7 & $p>0.05$ \\
\hline
\end{tabular}

Lethality - number of exited rats out of total number of rats in group expressed in percentage. Significance of the differences between the groups was estimated by Fisher's exact probability test. For the details see caption to Fig. 1

H
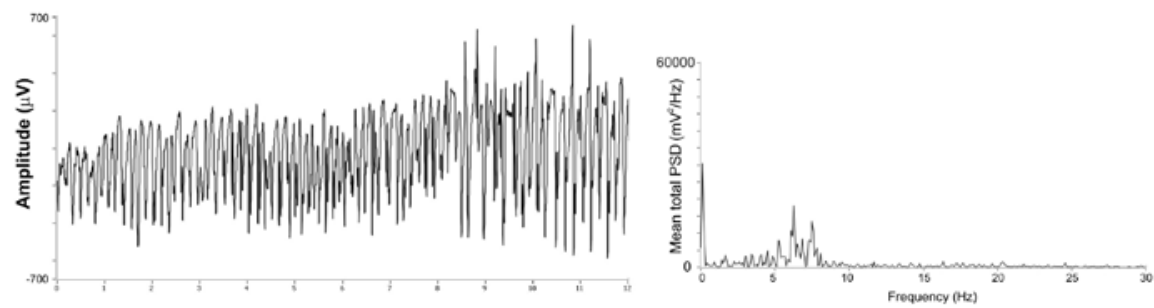

FH
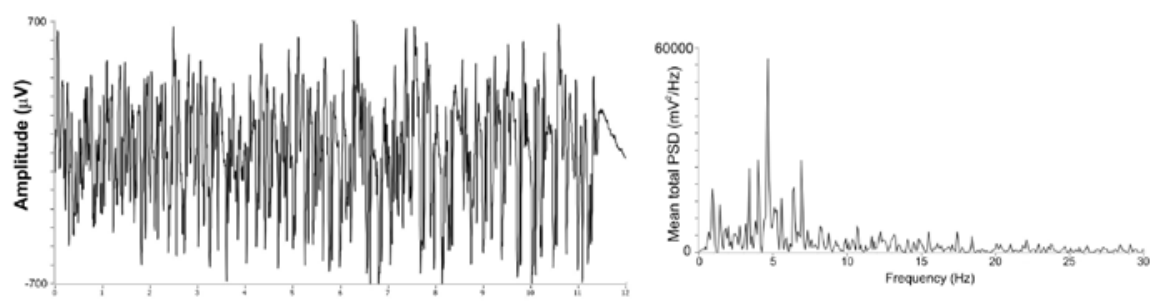

Time (s)

Fig. 3. Representative EEG tracings (the left panels) and corresponding power spectra density (the right panels) in experimental groups, recorded during grade 2 convulsions,

$45 \mathrm{~min}$ after DL homocysteine-thiolactone administration. For the details see caption to Fig. 1 
Brain $\mathrm{Na}^{+} / \mathrm{K}^{+}$-ATPase and $\mathrm{Mg}^{2+}$-ATPase activities

Administration of DL homocysteine-thiolactone produced a significant reduction of $\mathrm{Na}^{+} / \mathrm{K}^{+}-$ ATPase activity in all examined brain structures (the cortex, the hippocampus and the brain stem by $-64.94 \%, p<0.01,-83.89 \%, p<0.01$ and $-85.44 \%, p<0.01$, respectively) comparing to the control. Subchronic supplementation with folic acid, when administered alone, significantly increased the activity of this enzyme in the cortex $(+138.00 \%, p<0.01)$, the hippocampus $(+78.22 \%, p<0.05)$ and the brain stem $(+70.91 \%, p<0.05)$, compared to controls. When $\mathrm{H}$ was administered following subchronic supplementation with folic acid $\mathrm{Na}^{+} / \mathrm{K}^{+}$-ATPase activity significantly increased in the cortex $(+180.38 \% ; p<001)$ and the brain stem $(+89.09 \%, p<0.05)$ comparing to the $\mathrm{C}$; while in the hippocampus, the activity of this enzyme returned to the baseline values (Fig. 4A).

In animals treated with DL homocysteine-thiolactone the activity of $\mathrm{Mg}^{2+}$-ATPase was significantly elevated in the cortex $(+44.52 \%, p<0.05)$, while no significant changes in the activity of this enzyme were observed either in the hippocampus $(-5.56 \%, p>0.05)$ or in the brain stem $(+2.63 \%, p>0.05)$. Folic acid supplementation significantly increased the activity of $\mathrm{Mg}^{2+}$-ATPase in the cortex $(+261.27 \%, p<0.01)$, the hippocampus $(+108.33 \%, p<0.01)$, and the brain stem $(+68.42 \%, \mathrm{p}>0.05)$, comparing to the $\mathrm{C}$. In the FH group $\mathrm{Mg}^{2+}$-ATPase activity significantly increased in all examined structures: the cortex $(+311.31 \%, p<0.01)$, the hippocampus $(+108.33 \%, p<0.01)$ and the brain stem $(+147.38 \%, p<001)$, comparing to the C (Fig. 4B).

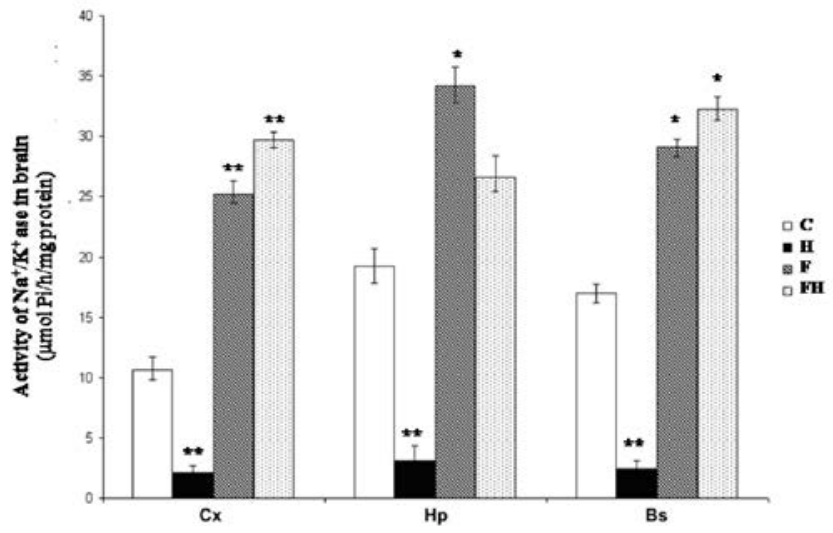

Fig. 4A. The effect of DL homocysteine-thiolactone $(\mathrm{H})$, supplementation with folic acid

( $5 \mathrm{mg} / \mathrm{kg}$ for 7 days) (F) and supplementation with folic acid prior to $\mathrm{H}$ administration $(\mathrm{FH})$ on $\mathrm{Na}^{+} / \mathrm{K}^{+}$-ATPase activity in different parts of brain $* p<0.05, * * p<0.01$ vs. $\mathrm{C}$

Cortex (Cx), hippocampus (Hp), brain stem (Bs)

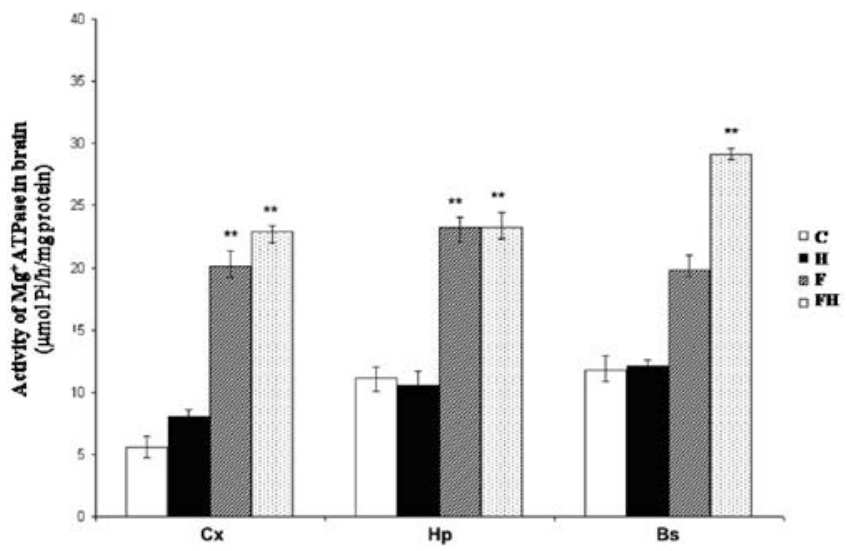

Fig. 4B. The effect of DL homocysteine-thiolactone $(\mathrm{H})$, supplementation with folic acid

( $5 \mathrm{mg} / \mathrm{kg}$ for 7 days) (F)

and supplementation with folic acid prior to $\mathrm{H}$ administration $(\mathrm{FH})$

on $\mathrm{Mg}^{2+}$-ATPase activity

in different parts of brain ** $p<0.01$ vs. C

Cortex (Cx), hippocampus (Hp), brain stem (Bs) 


\section{Discussion}

The link between epilepsy and folic acid is complex. Patients on antiepileptic drugs are prone to low folate and vitamin B12 and consequent hyperhomocysteinemia, which can promote excitotoxicity and lead to increased neuronal injury and cell death (1). On the other hand, folic acid has been accused of being a potential risk, for provoking seizures and poor seizure control (37).

In the present study, we investigated the effect of subchronic supplementation with folic acid on DL homocysteine-thiolactone induced seizures and $\mathrm{Na}^{+} / \mathrm{K}^{+}$-ATPase and $\mathrm{Mg}^{2+}$-ATPase activity in different CNS regions.

Folic acid plays an important role in neuronal development, neuroplasticity and in the maintenance of neuronal integrity. Studies have shown that hyperhomocysteinemia actually represents a measure of functional folate deficiency (18). Low folate status and elevated homocysteine are responsible for cerebrovascular, neurodegenerative and psychiatric disorders $(21,30)$. This detrimental effect can be attributed to increased generation of ROS, excitotoxicity and mitochondrial dysfunction which leads to apoptosis. Previous results from our laboratory have shown that folic acid works as an anticonvulsive agent in $\mathrm{H}$ induced seizures, when it is given acutely in large doses (27). These results are consistent with previous results regarding the role of folic acid in preventing neuronal death and excitotoxicity and it appears that folic acid is a potent inhibitor of kainic, NMDA receptors, nitric oxide and cyclic guanosine monophosphate synthesis (4).

The results presented here demonstrate that subchronic supplementation with folic acid $(5 \mathrm{mg} / \mathrm{kg})$ did not exacerbate behavioural characteristics of $\mathrm{H}$ induced seizures; incidence, latency, number and intensity of seizure episodes were not significantly different compared to H. Spectral power densities of ictal episodes were higher in the $\mathrm{FH}$ group, but not in a significant manner to be claimed as proconvulsive. Still, remains the question, is this discrepancy in the results due to the dose or the time dependent manner of administration of folic acid.

Studies have shown that excess folate has a direct neurotoxic effect and may function as endogenous excitatory amino acid (2). Recent findings of Budni et al. (5), suggested the role of folic acid in the modulation of neuronal excitability via inhibition of different types of $\mathrm{K}^{+}$ channels, which may explain why subchronic supplementation failed to produce an anticonvulsive effect on $\mathrm{H}$ induced seizures. Furthermore, we noticed that lethal outcomes in the FH group was higher 90 min after $\mathrm{H}$ injection and did not increase up to $24 \mathrm{~h}$ after $\mathrm{H}$. Although statistical significance was not attained when compared to the $H$, the mechanism should be examined in further experiments.

There is evidence that the nervous system response is related both to the dose and the duration of treatment, as well as the folate status of the patient (32). After ingestion, folic acid is reduced by dihydrofolate reductase and then converted to biologically active forms. If intake exceeds the body's ability to reduce folic acid, unmetabolized folic acid will be found in blood. There are concerns that exposure to unmetabolized folic acid may be associated with adverse effects (33) and high lethality outcomes 90 min after $\mathrm{H}$ injection.

Our previously published data, demonstrated a strong inhibitory effect of homocysteine thiolactone on the $\mathrm{Na}^{+} / \mathrm{K}^{+}$-ATPase activity in SPM of the rat hippocampus, the brain stem and the parietal cortex of rats without affecting the $\mathrm{Mg}^{2+}$-ATPase activity $(36,43)$. The results presented here demonstrate that subchronic supplementation with folic acid completely reversed the inhibitory effect of homocysteine thiolactone and even increased $\mathrm{Na}^{+} / \mathrm{K}^{+}$-ATPase activities in the cortex and the brain stem, compared to the baseline values. Inhibition of 
$\mathrm{Na}^{+} / \mathrm{K}^{+}$-ATPase by homocysteine may result from the oxidation of thiol groups, mediated by free radicals (25). On the other hand, folic acid and its active metabolites elicit direct antioxidative effects: it reduces superoxide anion production via NADPH oxidase, attenuates the xanthine oxidase activity, and restores SOD activity in hyperhomocysteinemic rats $(17,40)$.

Dietary therapies represent a potentially valuable adjunct to other conventional epilepsy treatments. On the other hand, dietary supplementation and fortification of cereal grain products with folic acid, imposes a need to examine the potential beneficial or adverse effects in patients with different medical conditions.

It is clear that the relationships between folate and health outcomes are complex; we need further investigation for a better understanding of the relevant biological mechanisms to avoid misinterpretation.

\section{REFERENCES}

1. Apeland T, Mansoor MA, Pentieva K, McNulty H, Seljeflot I, Strandjord RE: The effect of B-vitamins on hyperhomocysteinemia in patients on antiepileptic drugs. Epi. Res. 51, 237-247 (2002)

2. Baydar T, Papp A, Nagymajtényi L, Schulz H, Sahin G: Folate supplementation in rats: Does it cause behavioural and electrophysiological changes? Pteridines 13, 107-114 (2002)

3. Bingami A, Palladini C, Venturini G: Effect of cardiazol on sodium-potassium adenosine triphosphatase of the rat brain in vivo. Brain Res. 1, 413-414 (1966)

4. Brocardo PS, Budni J, Lobato KR, Kaster MP, Rodrigues AL: Antidepressant-like effect of folic acid: Involvement of NMDA receptors and L-arginine-nitric oxide-cyclic guanosine monophosphate pathway. Eur. J. Pharmacol. 598, 37-42 (2008)

5. Budni J, Freitas AE, Binfaré RW, Rodrigues AL: Role of potassium channels in the antidepressant-like effect of folic acid in the forced swimming test in mice. Pharmacol. Biochem. Behav. 101(1), 148-154 (2012)

6. Cohen RS, Blomber F, Berzins K, Siekevitz P: The structure of postsynaptic densities isolated from dog cerebral cortex: I. Overall morphology and protein composition. J. Cell Biol. 74, 181-203 (1977)

7. D'Anci KE, Rosenberg IH: Folate and brain function in the elderly. Curr. Opin. Clin. Nutr. Metab. 7, 659-664 (2004)

8. den Heijer T, Vermeer SE, Clarke R, Oudkerk M, Koudstaal PJ, Hofman A, Breteler MM: Homocysteine and brain atrophy on MRI of non-demented elderly. Brain 126: 170-175 (2003)

9. Djurić D, Jakovljević V, Rasic-Markovic A, Djuric A, Stanojlovic O: Homocysteine, folic acid and coronary artery disease: possible impact on prognosis and therapy. Indian J. Chest. Dis. Allied. Sci 50, 39-48 (2008)

10. Greenop KR, Miller M, de Klerk NH, Scott RJ, Attia J, Ashton LJ, Dalla-Pozza L, Bower C, Armstrong BK, Milne E: Maternal dietary intake of folate and vitamins B6 and B12 during pregnancy and risk of childhood brain tumors. Nutr. Cancer 66(5), 800-809 (2014)

11. Grisar T, Guillaume D, Delgado-Escueta AV: Contribution of Na+/K+-ATPase to focal epilepsy: a brief review. Epilepsy Res. 12, 141-149 (1992)

12. Hamid A, Wani NA, Kaur J: New perspectives on folate transport in relation to alcoholism-induced folate malabsorption - association with epigenome stability and cancer development. FEBS J. 276, 2175-2191 (2009).

13. Herrmann W, Obeid R: Homocysteine: a biomarker in neurodegenerative diseases. Clin. Chem. Lab. Med. 49, 435-441 (2011)

14. Ho PI, Ashline D, Dhitavat S, Ortiz D, Collins SC, Shea TB, Rogers E: Folate deprivation induces neurodegeneration: roles of oxidative stress and increased homocysteine. Neurobiol. Dis. 14, 32-42 (2003)

15. Ho PI, Collins SC, Dhitavat S, Ortiz D, Ashline D, Rogers E, Shea TB: Homocysteine potentiates beta-amyloid neurotoxicity: role of oxidative stress. J. Neurochem. 78(2), 249-253 (2001)

16. Horvat A, Nikezić G, Martinović JV: Estradiol binding to synaptosomal plasma membranes of rat brain regions. Experientia 51(1), 11-15 (1995)

17. Hwang SY, Siow YL, Au-Yeung KK, House JOK: Folic acid supplementation inhibits NADPH oxidasemediated superoxide anion production in the kidney. Am. J. Physiol. Renal. Physiol. 300(1), F189-F198 (2011)

18. Hyland K, Shoffner J, Heales SJ: Cerebral folate deficiency. Inherit. Metab. Dis. 33(5), 563-570 (2010) 
19. Kado DM, Karlamangla AS, Huang MH, Troen A, Rowe JW, Selhub J, Seeman TE: Homocysteine versus the vitamins folate, B12 and B6 as predictors of cognitive function in older high functioning adults: Mac Arthur studies of successful aging. Am. J. Med. 118, 161-167 (2005)

20. Kim YI: Methylenetetrahydrofolate reductase polymorphisms, folate, and cancer risk: a paradigm of genenutrient interactions in carcinogenesis. Nutr. Rev. 58, 205-217 (2000)

21. Kronenberg G, Colla M, Endres M: Folic acid, neurodegenerative and neuropsychiatric disease. Curr. Mol. Med. 9(3), 315-323 (2009)

22. Kruman II, Culmsee C, Chan SL, Kruman Y, Guo Z, Penix L, Mattson MP: Homocysteine elicits a DNA damage response in neurons that promotes apoptosis and hypersensitivity to excitotoxicity. J. Neurosci. 20, 6920-6926 (2000)

23. Lamers Y, Prinz-Langenohl R, Moser R, Pietrzik K: Supplementation with [6S]-5-methyltetrahydrofolate or folic acid equally reduces plasma total homocysteine concentrations in healthy women. Am. J. Clin. Nutr. 79, 473-478 (2004)

24. Lees GJ, Leong W: Brain lesions induced by specific and non-specific inhibitors of sodium-potassium ATPase. Brain Res. 649(1-2), 225-233 (1994)

25. Lees GJ: Contributory mechanisms in the causation of neurodegenerative disorders. Neurosci. 54, 287-322 (1993)

26. Lin Y, Desbois A, Jiang S, Hou ST: Group B vitamins protect murine cerebellar granule cells from glutamate/ NMDA toxicity. Neuroreport 224, 1-4 (2004)

27. Marković AR, Hrnčić D, Macut D, Stanojlović O, Djuric D: Anticonvulsive effect of folic acid in homocysteine thiolactone-induced seizures. Cell. Mol. Neurobiol. 31(8), 1221-1228 (2011)

28. Mastropaolo D, Camerman A, Camerman N: Folic acid: crystal structure and implications for enzyme binding. Science 210(4467), 334-336 (1980)

29. Mattson MP, Kruman II, Duan W: Folic acid and homocysteine in age-related disease. Ageing Res. Rev. 1, 95-111 (2002)

30. Morris MS: Folate, homocysteine, and neurological function. Nutr. Clin. Care 5(3), 124-132 (2002)

31. Nazki FH, Sameer AS, Ganaie BA: Folate: metabolism, genes, polymorphisms and the associated diseases. Gene 533(1), 11-20 (2013)

32. Niu J, Wang A, Ke Z, Zheng Z: Glucose transporter and folic acid receptor-mediated Pluronic P105 polymeric micelles loaded with doxorubicin for brain tumor treating. J. Drug Target 22(8), 712-723 (2014)

33. Obeid R, Hermann W: The emerging role of unmetabolized folic acid in human diseases: myth or reality? Curr. Drug Metab. 13(8), 1184-1195 (2012)

34. Perla-Kajan J, Twardowski T, Jakubowski H: Mechanisms of homocysteine toxicity in humans. Amino Acids 32, 561-572 (2007)

35. Picciano MF, McGuire MK: Use of dietary supplements by pregnant and lactating women in North America. Am. J. Clin. Nutr. 89(2), 663S-667S (2009)

36. Rasić-Marković A, Stanojlović O, Hrncić D, Krstić D, Colović M, Susić V, Radosavljević T, Djuric D: The activity of erythrocyte and brain $\mathrm{Na}^{+} / \mathrm{K}^{+}$and $\mathrm{Mg}^{2+}$-ATPases in rats subjected to acute homocysteine and homocysteine thiolactone administration. Mol. Cell. Biochem. 327(1-2), 39-45 (2009).

37. Reynolds E: Benefits and risks of folic acid to the nervous system. J. Neurol. Neurosurg. Psychiatry 72(5), 567-571 (2002)

38. Rydlewicz A, Simpson JA, Taylor RJ, Bond CM, Golden MH: The effect of folic acid supplementation on plasma homocyteine in an elderly population. Quart. J. Med. 95, 27-35 (2002)

39. Sachdev PS: Homocysteine and brain atrophy. Prog. Neuropsychopharmacol. Biol. Psychiatry 29, 1152-1161 (2005)

40. Sarna LK, Wu N, Wang P, Hwang SY, Siow YL: Folic acid supplementation attenuates high fat diet induced hepatic oxidative stress via regulation of NADPH oxidase. Can. J. Physiol. Pharmacol. 90(2), 155-165 (2012)

41. Scott TM, Tucker KL, Bhadelia A, Benjamin B, Patz S, Bhadelia R, Liebson E, Price LL, Griffith J, Rosenberg I, Folstein MF: Homocysteine and B vitamins relate to brain volume and white-matter changes in geriatric patients with psychiatric disorders. Am. J. Geriatr. Psychiatry 12, 631-638 (2004).

42. Stanojlović O, Rasić-Marković A, Hrncić D, Susić V, Macut D, Radosavljević T, Djuric D: Two types of seizures in homocysteine thiolactone-treated adult rats, behavioral and electroencephalographic study. Cell. Mol. Neurobiol. 29, 329-339 (2009)

43. Streck EL, Zugno A, Tagliari B, Wannmacher C, Wajner M, Wyse AT: Inhibition of Na+/K+-ATPase activity by the metabolites accumulating in homocystinuria. Metab. Brain Dis. 17, 83-91 (2002) 
44. Tagliari B, Zamin L, Salbego CG, Netto CA, Wyse AT: Hyperhomocysteinemia increases damage on brain slices exposed to in vitro model of oxygen and glucose deprivation: prevention by folic acid. Int. J. Dev. Neurosci. 24 (4), 285-291 (2006)

45. Tjiattas L, Ortiz DO, Dhivant S, Mitton K, Rogers E, Shea TB: Folate deficiency and homocysteine induce toxicity in cultured dorsal root ganglion neurons via cytosolic calcium accumulation. Aging Cell 3(2), 71-76 (2004)

46. Towle AC, Sze PY: Inactivation by Na+, K+-ATPase of cytosol glucocorticoid receptors from rat brain and liver. Mol. Cell. Biochem. 52(2), 145-151 (1983)

47. Wyse AT, Streck EL, Worm P, Wajner A, Ritter F, Netto CA: Preconditioning prevents the inhibition of Na+, K+-ATPase activity after brain ischemia. Neurochem. Res. 25, 969-973 (2000)

48. Vasić V, Jovanović D, Krstić D, Nikezić G, Horvat A, Vujisić L, Nedeljković N: Prevention and recovery of $\mathrm{CuSO}_{4}$-induced inhibition of $\mathrm{Na}+\mathrm{K}+$-ATPase in rat brain synaptosomes by EDTA. Toxicol. Lett. 110, 95-104 (1999)

49. Zeisel SH: Is maternal diet supplementation beneficial? Optimal development of infant depends on mother's diet. Am. J. Clin. Nutr. 89(2), 685S-687S (2009) 